\title{
Correlation of Glasgow Coma Scale Score at Hospital Admission with Stroke Hemorrhagic Patient Mortality at Hasan Sadikin Hospital
}

\author{
Ary S Hartanto*, Andi Basuki**, Cep Juli** \\ *Faculty of Medicine Padjadjaran University \\ ** Department of Neurology Faculty of Medicine Padjadjaran University \\ - Hasan Sadikin General Hospital \\ Jl. Prof. Eyckman No. 38 Bandung 40161 Indonesia \\ Email:arysetioo@gmail.com
}

\begin{abstract}
Stroke is the most common cause of death in Indonesia. Stroke is divided into ischemic and hemorrhagic stroke. Hemorrhagic stroke has a higher risk of death than ischemic stroke. Hemorrhagic stroke can disrupt patient's consciousness. The Glasgow Coma Scale (GCS) is a scale that is widely used to assess the level of consciousness. Accurate predictors can help doctors determine prognosis and treatment for stroke patient. This study was conducted to determine the correlation of GCS scores at the time of hospital admission and mortality of hemorrhagic stroke patients at Hasan Sadikin Hospital. This is a retrospective cohort analytic study involving 134 subjects. Data were analyzed using Kolmogorov-Smirnov's and Fisher's analysis test with significance of $p<0.05$. From the results of the study, the p-value was 0.00 , subjects with GCS score somnolence (12-14) had six times higher risk in mortality $(P=0.02$, $R R=6.38)$ and subjects with GCS score sopor and coma (3 - 11) had twenty four times higher risk in mortality $(P=0.00, R R=23.85)$. We concluded that a decreased score of GCS at the time of hospital admission was associated with increased risk of death in hemorrhagic stroke patients at Hasan Sadikin Hospital.
\end{abstract}

Keywords: Glasgow Coma Scale, hemorrhagic stroke, mortality 


\title{
Hubungan Skor Skala Koma Glasgow pada Saat Masuk Rumah Sakit dengan Kematian Pasien Stroke Pendarahan di Rumah Sakit Hasan Sadikin
}

\author{
Ary S Hartanto*, Andi Basuki**, Cep Juli** \\ *Fakultas Kedokteran Universitas Padjadjaran \\ ** Departemen Saraf Fakultas Kedokteran Universitas Padjadjaran \\ - Rumah Sakit Umum Hasan Sadikin Bandung \\ J1. Prof. Eyckman No.38 Bandung 40161 Indonesia \\ Email : arysetioo@gmail.com
}

\begin{abstract}
Abstrak
Stroke merupakan penyebab kematian terbanyak di Indonesia. Stroke terbagi menjadi stroke iskemik dan pendarahan. Stroke pendarahan memiliki risiko kematian yang lebih tinggi dibandingkan stroke iskemik. Stroke pendarahan dapat mengganggu sistem ARAS (Ascending Reticular Activating System) dan dapat menyebabkan iskemia otak yang berujung pada penurunan kesadaran seseorang. Skala Koma Glasgow (SKG) merupakan skala yang digunakan secara luas untuk menilai tingkat kesadaran. Prediktor yang akurat dapat membantu dokter dalam menentukan prognosis dan penanganan pasien stroke. Penelitian ini dilakukan untuk mengetahui hubungan antara skor SKG pada saat masuk rumah sakit dengan kematian pasien stroke pendarahan di Rumah Sakit Hasan Sadikin. Penelitian ini merupakan studi analitik retrospektif kohort yang melibatkan 134 subjek. Data dianalisis menggunakan uji analisis Kolmogorov-Smirnov dan Fisher dengan signifikansi $\mathrm{p}<0,05$. Dari hasil penelitian didapatkan nilai p sebesar 0,00 ; subjek dengan skor somnolen (12-14) berisiko enam kali lebih tinggi mengalami kematian $(\mathrm{P}=0,02 ; \mathrm{RR}=6,38)$ dan subjek dengan skor sopor dan koma (3-11) memiliki risiko 24 kali lebih tinggi mengalami kematian $(P=0,00 ; R R=23,85)$. Dari penelitian ini disimpulkan bahwa penurunan skor SKG pada saat masuk rumah sakit berhubungan dengan peningkatan risiko kematian pada pasien stroke pendarahan di Rumah Sakit Hasan Sadikin.
\end{abstract}

Kata Kunci: Skala Koma Glasgow, stroke pendarahan, kematian 


\section{Pendahuluan}

Stroke merupakan penyebab kematian terbanyak di Indonesia. Prevalensi stroke terus meningkat di Indonesia. ${ }^{1}$ Stroke secara umum terbagi menjadi stroke iskemik dan stroke pendarahan. ${ }^{2}$ Stroke pendarahan memiliki tingkat keparahan dan risiko kematian yang lebih tinggi dibandingkan dengan stroke iskemik. $^{3}$ Stroke pendarahan dapat menyebabkan penurunkan kesadaran yang diakibatkan oleh terganggunya sistem ARAS (Ascending Reticular Activating System) dan turunnya perfusi menuju otak. ${ }^{4-7}$ Skala Koma Glasgow (SKG) merupakan salah satu skala yang sudah tervalidasi dan digunakan secara luas untuk menilai tingkat kesadaran. SKG melibatkan tiga aspek dalam pengukurannya yaitu pembukaan mata, respon verbal, dan respon motorik. Setiap respon tersebut akan ditetapkan menjadi satuan angka, semakin buruk responnya maka semakin kecil angka yang ditetapkan. ${ }^{8}$ SKG merupakan alat yang terpercaya untuk mengukur tingkat kesadaran pada pasien stroke. ${ }^{9}$ Skor SKG merupakan prediktor yang akurat untuk melihat mortalitas pada pasien stroke iskemik dan juga pada pasien stroke pendarahan. ${ }^{10,11}$

Prediksi yang akurat untuk keluaran dari stroke merupakan hal penting. Prediksi yang akurat dapat membantu menetapkan penanganan pasien dengan baik dan membantu dalam pemberian informasi yang tepat kepada pasien dan keluarga pasien. ${ }^{12}$ Berdasarkan latar belakang tersebut peneliti tertarik untuk meneliti hubungan skor SKG saat masuk rumah sakit dengan kematian pasien stroke pendarahan di Rumah Sakit Hasan Sadikin. Tujuan penelitian ini adalah untuk mengetahui hubungan antara skor SKG pada saat masuk rumah sakit dengan kematian pasien stroke pendarahan di Rumah Sakit Hasan Sadikin.

\section{Metode}

Penelitian ini merupakan studi analitik kohort retrospektif yang dilakukan pada bulan Desember 2018. Subjek dari penelitian ini adalah pasien yang dirawat di Departemen Saraf RSUP Dr. Hasan Sadikin Bandung pada periode Januari - Desember 2017. Penelitian ini telah mendapat persetujuan dari Komite Etik Penelitian Kesehatan Fakultas Kedokteran Universitas Padjadjaran (No. 1157/UN6.KEP/EC/2018) dan Komite Etik RSUP Dr. Hasan Sadikin Bandung (No. LB.02.01/X.2.2.1/21805/2018)

Data penelitian ini diambil dari rekam medis dengan metode total sampling. Terdapat 134 data pasien yang menjadi subjek penelitian. Kriteria inklusi penelitian ini berupa seluruh data rekam medis pasien yang terdiagnosis pasien stroke pendarahan, memiliki nilai skor SKG pada saat masuk rumah sakit, dan memiliki keluaran hidup atau mati pada saat keluar rumah sakit di Departemen Saraf RSUP Dr. Hasan Sadikin Bandung. Kriteria eksklusi berupa rekam 


\section{Research Article}

medis pasien yang terdiagnosis stroke campuran dan rekam medis pasien dengan riwayat stroke sebelumnya. Data yang telah diseleksi diolah menggunakan program IBM SPSS versi 23 dan dilakukan uji Kolmogorov-Smirnov dan Fisher untuk mengetahui hubungan skor SKG dengan kematian pasien stroke perdarahan. Signifikansi uji ditentukan oleh nilai $\mathrm{p}<0,05$. Hasil analisis akan disajikan dalam bentuk tabel.

\section{Hasil}

Tabel 1 Karakteristik Subjek Penelitian

\begin{tabular}{llcc}
\hline & Variabel & $\begin{array}{c}\text { Frekuensi } \\
(\mathbf{N}=\mathbf{1 3 4})\end{array}$ & Proporsi (\%) \\
\hline Jenis kelamin & Laki-laki & 60 & $45,8 \%$ \\
& Perempuan & 74 & $55,2 \%$ \\
\hline & Total & 134 & $100 \%$ \\
\hline Usia (tahun) & $<40$ tahun & 10 & $7,5 \%$ \\
& $40-49$ tahun & 21 & $15,7 \%$ \\
& $50-59$ tahun & 53 & $39,6 \%$ \\
& $\geq 60$ Tahun & 50 & $37,3 \%$ \\
\hline Skor Skala & Total & 134 & $100 \%$ \\
Koma Glasgow & Compos Mentis (15) & 28 & $20,9 \%$ \\
& Somnolen (12-14) & 79 & $59,0 \%$ \\
& Sopor (8-11) & 22 & $16,4 \%$ \\
& Koma (3-7) & 5 & $3,7 \%$ \\
\hline
\end{tabular}

Tabel 1 menunjukan karakteristik subjek penelitian yang berjumlah 134 orang. Dari 134 subjek penelitian terdapat $60(44,8 \%)$ subjek berjenis kelamin laki-laki dan 74 (55,2\%) subjek berjenis kelamin perempuan. Subjek terbanyak ada pada kategori umur 50-59 tahun sejumlah $53(39,6 \%)$ yang diikuti oleh kategori usia sesuai urutan yaitu $\geq 60$ tahun, 40-49 tahun dan $<40$ tahun. Somnolen merupakan kategori skor SKG terbanyak pada penelitian ini dengan jumlah 79 (59\%), sedangkan Koma merupakan kategori skor SKG paling sedikit.

Tabel 2 Hubungan Status Mortalitas dengan Skor Skala Koma Glasgow

\begin{tabular}{|c|c|c|c|}
\hline \multirow[b]{2}{*}{ Variabel } & \multicolumn{2}{|c|}{ Output } & \multirow[b]{2}{*}{ Nilai - p } \\
\hline & $\begin{array}{l}\text { Hidup } \\
(\mathrm{n}=92)\end{array}$ & $\begin{array}{c}\text { Mati } \\
(n=42)\end{array}$ & \\
\hline Skor Skala Koma Glasgow & & & 0,00 \\
\hline Compos Mentis & $27(96,4 \%)$ & $1(3,6 \%)$ & \\
\hline Somnolen & $61(77,2 \%)$ & $18(22,8 \%)$ & \\
\hline Sopor & $4(18,2 \%)$ & $18(81,8 \%)$ & \\
\hline
\end{tabular}




\begin{tabular}{|c|c|c|c|}
\hline Variabel & & & Nilai - p \\
\hline Koma & $0(0 \%)$ & $5(100 \%)$ & \\
\hline
\end{tabular}

Tabel 2 menunjukan hubungan status mortalitas dengan skor SKG. Hasil analisis menunjukkan adanya hubungan yang signifikan antara status mortalitas dengan skor SKG berdasarkan nilai $\mathrm{p}=0,00(\mathrm{p}<0,05)$. Pada Tabel 2 terdapat satu sel yang menunjukkan hasil 0 sehingga peneliti memutuskan untuk melakukan penggabungan sel sopor dengan koma untuk mengamati Relative Risk.

Tabel 3 Hubungan Status Mortalitas dengan Skor Skala Koma Glasgow setelah Dilakukan Penggabungan Sel

\begin{tabular}{lcccc}
\hline \multirow{2}{*}{ Variabel } & \multicolumn{2}{c}{ Output } & & \\
\cline { 2 - 3 } & $\begin{array}{c}\text { Hidup } \\
(\mathbf{n}=\mathbf{9 2})\end{array}$ & $\begin{array}{c}\text { Mati } \\
(\mathbf{n}=\mathbf{4 2})\end{array}$ & & \\
\hline Skor Skala Koma - $\mathbf{p}$ & $\mathbf{R R}$ \\
$\quad$ Compos Mentis & $27(96,4 \%)$ & $1(3,6 \%)$ & & 1,00 \\
Somnolen & $61(77,2 \%)$ & $18(22,8 \%)$ & 0,02 & 6,38 \\
Sopor \& Koma & $4(14,8 \%)$ & $23(85,2 \%)$ & 0,00 & 23,85 \\
\hline
\end{tabular}

Hasil analisis pada tabel 3 menunjukan terdapat hubungan $(\mathrm{p}<0,05)$ antara skor SKG somnolen (12-14) dengan kematian pasien stroke pendarahan. Subjek dengan skor SKG somnolen (12-14) memiliki risiko enam kali lebih tinggi untuk mengalami kematian dibandingkan subjek dengan skor SKG compos mentis.

Pada tabel 3 juga dapat diamati bahwa terdapat hubungan $(\mathrm{p}<0,05)$ antara skor SKG sopor \& koma (3-11) dengan kematian pasien stroke pendarahan. Subjek dengan skor SKG sopor \& koma (3-11) memiliki risiko dua puluh empat kali lebih tinggi untuk mengalami kematian dibandingkan dengan subjek dengan skor SKG compos mentis (15).

\section{Diskusi}

Terdapat 134 rekam medis yang menjadi subjek penelitian ini. Subjek penelitan didominasi oleh jenis kelamin perempuan sebesar 55,2\%. Hal ini serupa dengan penelitian lain yang dilakukan di Rumah Sakit Daerah dr. Soebandi Jember yang menemukan bahwa subjek penelitian perempuan sebesar $59,4 \%$ dari total 101 subjek penelitian. ${ }^{13}$ Pada tabel 1 juga dapat diamati umur subjek penelitian memiliki jumlah terbanyak pada kategori umur 50-59 tahun yaitu sebesar $39,6 \%$ dari total subjek. Penelitian lain yang dilaksanakan di Utara India 


\section{Research Article}

menemukan bahwa usia 50 - 60 tahun adalah kelompok usia terbanyak untuk kejadian stroke pendarahan akut. ${ }^{14}$ Berdasarkan data rekam medis yang didapatkan, klasifikasi skor SKG terbanyak adalah somnolen (12 - 14) dengan jumlah 59\%. Penelitian yang dilakukan di Inggris menyatakan hal yang serupa bahwa pasien terbanyak ada pada klasifikasi skor SKG sebesar 1415 sejumlah 48,3\% dan 9 - 13 sejumlah $24,1 \%$ dari 1175 jumlah sampel. ${ }^{15}$

Hasil uji Kolmogorov-Smirnov menunjukan secara statistik skor SKG pada saat masuk rumah sakit berhubungan terhadap mortalitas pasien stroke pendarahan dengan nilai $\mathrm{p}$ sebesar $0,00(p<0,05)$. Hasil ini menunjukan semakin rendah skor SKG pada saat masuk rumah sakit berhubungan dengan peningkatan risiko kematian pasien stroke pendarahan. Hasil ini serupa dengan penelitian yang dilakukan di RSUD DR. Soedarso Pontianak yang menyatakan terdapat hubungan antara rendahnya skor SKG dengan peningkatan risiko kematian pada pasien stroke pendarahan intraserebral. ${ }^{16}$

Kematian pada pasien stroke pendarahan terjadi akibat peningkatan tekanan intrakranial dan iskemia otak. Peningkatkan tekanan intrakranial dan iskemia otak ini disebabkan adanya darah yang keluar dari pembuluh darah dan mengisi ruang di otak. Berkurangnya suplai darah menuju ke otak dapat menyebabkan iskemia otak sedangkan penekanan yang diakibatkan oleh darah yang mengisi ruang di otak dapat menyebabkan tertekannya ARAS (Ascending Reticular Activation System). Kedua mekanisme tersebut berkaitan dengan kesadaran pasien stroke pendarahan. Semakin parah derajat stroke perdarahan maka tingkat kesadaran pasien akan semakin menurun. ${ }^{4-7}$ Tingkat kesadaran pasien dinilai berdasarkan skor SKG pada saat masuk rumah sakit. ${ }^{8,9}$ Skor SKG pada saat masuk rumah sakit berhubungan dengan kematian pasien stroke pendarahan.

Subjek dengan skor SKG somnolen (12-14) memiliki risiko kematian sebesar enam kali lebih besar daripada subjek dengan skor SKG compos mentis $(\mathrm{p}=0,02 ; \mathrm{RR}=6,38)$. Sedangkan subjek dengan skor SKG sopor dan koma (3-11) memiliki risiko kematian sebesar 24 kali lebih besar daripada subjek dengan skor SKG compos mentis $(p=0,00 ; R R=23,85)$.

Hasil Penelitian yang dilakukan di RSUD DR. Soedarso Pontianak menunjukan hasil yang serupa bahwa pasien stroke pendarahan intraserebral dengan skor SKG 3-8 memiliki risiko 31 kali untuk mengalami mortalitas dibandingkan dengan pasien dengan skor SKG $>8(p=<0,001$; $\mathrm{OR}=31,40) .{ }^{16}$ Hasil penelitian lain yang dilakukan di Thailand menunjukan bahwa pasien stroke pendarahan intraserebral dengan skor SKG 3-4 memiliki risiko 10 kali untuk mengalami mortalitas dibandingkan dengan pasien dengan skor SKG $>4(\mathrm{p}=0,001 ; \mathrm{OR}=10) .{ }^{17}$ 


\section{Research Article}

\section{Simpulan}

Pada penelitian ini dapat disimpulkan penurunan skor SKG pada saat masuk rumah sakit berhubungan dengan peningkatan risiko kematian pada pasien stroke pendarahan di Rumah Sakit Hasan Sadikin.

\section{Daftar Pustaka}

1. Badan Penelitian dan Pengembangan Kesehatan. Riset Kesehatan Dasar (RISKESDAS) 2013. Lap Nas 2013. 2013;1-384.

2. Zunt JR. Adams and Victor'S Principles of Neurology. 10th editi. Vol. 74, Neurology. Mc Graw and Hill; 2014. 1400 p.

3. Benjamin EJ, Blaha MJ, Chiuve SE, Cushman M, Das SR, Deo R, et al. Heart disease and stroke statistics-2017 Update: A Report From the American Heart Association. Circulation. 2017 Mar 7;135(10):e146-603.

4. Aguilar MI, Brott TG. Update in intracerebral hemorrhage. The Neurohospitalist. 2011;1(3):148-59.

5. Suwatcharangkoon S, Meyers E, Falo C, Schmidt JM, Agarwal S, Claassen J, et al. Loss of consciousness at onset of subarachnoid hemorrhage as an important marker of early brain injury. JAMA Neurol. 2016;73(1):28-35.

6. Jang SH, Lim HW, Yeo SS. Injury of the ascending reticular activating system by transtentorial herniation in a patient with intracerebral haemorrhage: A diffusion tensor tractography study. J Neurol Neurosurg Psychiatry. 2015;86(10):1164-6.

7. Jang SH, Kim HS. Aneurysmal subarachnoid hemorrhage causes injury of the ascending reticular activating system: Relation to consciousness. Am J Neuroradiol. 2015;36(4):667-71.

8. Teasdale G, Maas A, Lecky F, Manley G, Stocchetti N, Murray G. The Glasgow Coma Scale at 40 years: standing the test of time. Lancet Neurol. 2014;13(8):844-54.

9. Amirudin MS. The realiabilty of Glasgow Coma Scale examination in stroke. Univ Gajah Mada. 2014;1-17.

10. Mansour OY, Megahed MM, Abd Elghany EHS. Acute ischemic stroke prognostication, comparison between Glasgow Coma Score, NIHS Scale and Full Outline of UnResponsiveness Score in intensive care unit. Alexandria J Med. 2015;51(3):247-53.

11. Glasgow Coma Scale predicts 30-day mortality after ICH [Internet]. Medscape. 2012 [Cited 13 December 2018]. Available from: https://www.medscape.com/viewarticle/765157

12. Counsell C, Dennis M, Mcdowall M, Warlow C. Predicting outcome after acute and subacute stroke development and validation of new prognostic models. $J$ Neurol Neurosurg Psychiatry.2002;52(5):1041-7.

13. Darotin R, Nurdiana, Nasution TH. Analisis faktor prediktor mortalitas stroke hemoragik di Rumah Sakit Daerah dr. Soebandi Jember. NurseLine J. 2017;2(2):134-45.

14. Baidya OP, Tiwari S, Usman K. Clinical profile of acute hemorrhagic stroke patients: a study in tertiary care hospital in Northern India. Int J Res Med Sci. 2014;22(44):1507-10.

15. Parry-Jones AR, Abid KA, Di Napoli M, Smith CJ, Vail A, Patel HC, et al. Accuracy and clinical usefulness of intracerebral hemorrhage grading scores: A direct comparison in a UK population. Stroke. 2013;44(7):1840-5.

16. Dinna Hanifah, Dyan Roshinta Laksmi Dewi SNYRS. Pengaruh volume perdarahan dan Skor Glasgow Coma Scale (GCS) saat masuk rumah sakit terhadap kejadian mortalitas pada pasien stroke perdarahan intraserbral di RSUD DR.Soedarso Pontianak. J Mhs PSPD FK Univ Tanjungpura. 2015;119(3):859-67.

17. Muengtaweepongsa S, Seamhan B. Predicting mortality rate with ICH score in Thai intracerebral hemorrhage patients. Neurol Asia. 2013;18(2):131-5. 